\title{
Elderly Lung Cancer Patients and Radiochemotherapy: A Review
}

\author{
Francesco Fiorica ${ }^{*}$, Antonio Stefanelli, Silvia Princivalle, Giuliana Pascale, Francesco Cartei
}

Department of Radiation Oncology, University Hospital Ferrara, Ferrara, Italy.

Email: *francesco.fiorica@unife.it

Received July $18^{\text {th }}, 2012$; revised August $20^{\text {th }}, 2012$; accepted September $4^{\text {th }}, 2012$

\begin{abstract}
More than $60 \%$ of lung cancer patients in Europe and the USA are older than 65 years at the time of diagnosis. Despite this, elderly patients are generally under-represented in clinical trials. That being so, a general consensus on how to treat elderly patients is still far from being achieved. In this review, we address some of the issues and challenges surrounding the treatment of older cancer patients and radiochemotherapy. We discuss the existing evidence related to radiochemotherapy in the elderly, focusing primarily on the lung cancer (NSCLC and SCLC) most commonly seen in older patients, and making general treatment recommendations.
\end{abstract}

Keywords: Radiochemotherapy; Lung Cancer; Elderly Patients; Geriatric Oncology; Clinical Trials

\section{Introduction}

Lung cancer is the leading cause of cancer deaths in the United States and worldwide [1] and it is a typical cancer of elderly patients. Incidence data from the National Cancer Institute's (NCI) surveillance epidemiology and results (SEER) have shown that older persons have a 10 times greater risk of developing lung cancer than those with an age of less than 65 years.

As the survival of elderly population increases in developed countries worldwide, it is expected that oncologists will be increasingly confronted with the therapeutic challenge of an elderly patient presenting with NSCLC or SCLC. It is by now widespread that radiochemotherapy is standard treatment for unresectable non small cell lung cancerand for small cell lung cancer; however in elderly cancer patients there is no clear evidence of safety and efficacy of radiochemotherapy approach. Manly, elderly patients are underrepresented in randomized clinical trials and those treated are normally without significant comorbidity and with a good functional organ reserve. Since elderly patients are an extremely heterogeneous population, subjects can vary from very fit to not being able to live independently due to co-morbidities, it is not so clear whether the toxicity of treatment is justified by the level gained as measured by life prolongation and whether co-morbidities can influence the acute and late toxicities due to radiochemotherapy. Nevertheless, patients who have reached their 80th year

\footnotetext{
${ }^{*}$ Corresponding author.
}

still have a mean life expectancy of seven years for men and nine years for women [2].

Age alone is not a sufficient reason to withhold radiochemotherapy treatment. Although there is a lack of clinical trials to drive evidence-based decision making in the elderly lung cancer patients, we review some of the important studies germane to the lung cancer radiochemotherapy treatment in elderly patients.

\section{Elderly Cancer Patients}

Traditionally the cut-off point at which an adult is considered "elderly" is 65 years. However, it is increasingly recognised that aging is a highly individualised process and all the changes involved in this process cannot be predicted solely on the basis of chronologic age. Indeed, at the age of 75 years, some will be as fit if not even more fit than many at the age of 60 years [3]. Efficacy/ toxicity ratio of an oncological treatment is clearly related to biological age and frail patients can be young [4]. Clinical evaluation of age should account for the diversity in terms of life-expectancy, incidence and prevalence of disease, degree of functional dependency, cognition, emotions and socio-economic resources [5]. The most studied instrument to provide information for risk stratification of elderly cancer patients is the comprehensive geriatric assessment (CGA). This assessment is based on evaluation of functional status, co-morbidities, polypharmacy, nutritional status, cognitive function, physiological status, socio-economic issues and geriatric syndromes. 
Each CGA may aid in personalising care for the patient with cancer [6]. Thereafter, patient's tolerance to radiochemotherapy can be assessed and monitoring can be performed.

\section{Rationale of Cominbing Radiotherapy and Chemotherapy in Clinical Practice}

Combined modality therapy has become a standard treatment for lung cancer. There are two main reasons to combine chemotherapy and external beam irradiation to improve therapeutic ratio $[7,8]$ :

- Spatial cooperation two anti-tumor agents act independently, controlling primary tumor (radiotherapy) and distant (micro-)metastases (chemotherapy);

- Enhancement of radiation effects produces a greater anti-tumor response than would be expected from the response achieved with radiotherapy used separately.

Spatial cooperation is effective if both anti-cancer modalities can be used at effective dosages, so that no interaction between radiotherapy and chemotherapy is required and differing toxicities are needed. This hypothesis underlies sequential radio-chemotherapy studies.

Besides independent cell killing of both modalities, chemotherapy may synchronize cells in a vulnerable phase for radiotherapy, decrease repopulation after radiotherapy, and enhance re-oxygenation by shrinking a tumor, which is advantageous for radiotherapy. However, this concept has failed in most clinical trials, metaanalyses, clearly, demonstrated inferiority of sequential approach in non small [9] and small cell lung cancer [10] compared to concomitant approach.

Probably, chemotherapy induces a fast repopulation of tumor cells [11] obtaining a rapid tumor progression between the end of chemotherapy and the start of radiotherapy. Otherwise, chemotherapy increases the number of quiescent cells that are as well radioresistant.

Enhancement of radiation with concomitant chemotherapy increases the effects in the irradiated volume leading to an increased local tumor control probably related to reduction of overall treatment time and therefore minimising the risk of repopulation. This increased tumor control can lead to an improved overall survival. However, cytostatic drugs, used as radiosensitiziers (cisplatin, 5-fluorouracil, taxanes) can increase damage to normal tissues. A therapeutic benefit is only achieved if enhancement of the tumor response is greater than that for normal tissues.

\section{Tolerance of Radiotherapy and Chemotherapy in Elderly Patients}

Combining radiotherapy and chemotherapy can result in increased therapeutic activity but also in increased toxicity, in fact:
- Effects of radiotherapy can be increased by chemotherapy on tumor and organ at risk;

- Effects of chemotherapy on target organ can be increased by radiotherapy;

- Independent injuries can be caused by the individual treatment modality in the same organ which can combine to increase the resulting dysfunction;

- An injury can be produced that is not commonly seen with either modality alone.

One of the reasons for difference in cancer treatment of elderly patients is the fear that advanced age may be associated with a reduced tolerance of treatment.

Data related to treatment tolerance in elderly patients are scarce, mainly because elderly patients are under represented in oncological clinical trials (account for only $25 \%)$.

Along with increasing age a decrease in physiologic reserve is observed. This is a complex process that varies in how it affects different people and even different organs. Moreover, this process is accelerated by the development of intercurrent illness. Elderly patients have a high prevalence of diseases, about $80 \%$ having three or more chronic conditions. It is likely that this population is compensated under normal condition, but when a patient is subjected to a stress, there may be inadequate functional reserve. Certainly, a combined radio-chemotherapy program represents a systemic and loco-regional distress. Its impact on daily functioning or its long-term impact on organ functions may be very important in many of these elderly patients. Therefore, it is essential to acquire a multidisciplinary assessment of patients in order to understand the clinical state of the individual and functional organ reserve independently from the diagnosis of cancer [12]. Obviously, evaluation of co-morbidity is very important in geriatric functional assessment, in order to recognise potentially treatable conditions, to assess functional reserve and to estimate life expectancy.

Co-morbidity scores can be divided into two groups: those that have been validated in elderly people but not in malignant disease (geriatric index of co-morbidity [GIC] [13] and those that have been developed in elderly people and validated in patients with cancer (adult comorbidity evaluation-27 [ACE-27] [14], cumulative illness rating scale for geriatrics [CIRS-G] [15], and the Charlson index [16]. After geriatric assessment, patients should be divided in fit, vulnerable, or frail. These categories of patients have different physiological reserves to tolerate a course of combined radiochemotherapy [17]. Frail patients have a poor prognosis, present high toxicity with standard treatments, and are candidates to palliative treatments. Physiologically fit patients are able to tolerate radical treatments, and may be treated similarly to younger patients. Vulnerable patients are those with reducted functional reserve and partial limitations, and may 
be candidates for customized radiotherapy and chemotherapy treatment according to organ functional reserve.

That being so, elderly patients require therapeutic strategies adapted to their individual risk profile, scoring and monitoring physiological organ reserve and co-morbidities.

\section{Non Small Cell Lung Cancer}

NSCLC is a predominant disease in elderly patients, with a median age at diagnosis of 71 years. $20 \%$ of lung cancer-related deaths occur in patients aged $\geq 80$ years [18]. Nevertheless, no clinical trials are designed specifically for elderly NSCLC patients. Population-based analyses also report an undertreatment of these patients, only $46 \%$ of individuals aged $>65$ with NSCLC IIIb and IV stage received RT, $24 \%$ of them combined with chemotherapy [19]. In 2000, the Radiation Therapy Oncology Group performed a recursive partitioning analysis of 1999 patients enrolled in various protocols and identified age as a factor in therapeutic outcome in locally advanced NSCLC [20]. The susceptibility of combined radio-chemotherapy approach for elderly patients has only been studied in subset analyses of clinical trials in a post hoc manner.

The North Central Cancer Treatment Group NCCTG [21] conducted a randomized clinical trial to compare the results of adding chemotherapy to once-daily or twicedaily radiotherapy. Despite increased toxicity, elderly patients have 2- and 5-year survival rates which are equivalent to younger individuals. Similarly, evaluating elderly patients of two randomized clinical trials of Cancer and Leukemia Group B (CALGB), Rocha Lima et al. showed that the efficacy outcomes were comparable between patients aged 70 years and older and those aged less than 70 years. None of the patients included in these studies were older than 80 years of age. Same results were reported in the subset analyses of the RTOG 94-10 study [22].

In addition to these subset analyses, several reports have been published with recommendations on the treatment of elderly. Two retrospective analyses in patients receiving combined modality therapy showed no negative impact of age on treatment tolerance, response to treatment, or survival [23,24]. Semrau et al. [25], retrospectively examined 66 patients with inoperable NSCLC suffering from substantial co-morbidities or at advanced age ( $>70$ years) treated with chemo-radiotherapy, analysed according to co-morbidity, and concluded that chemo-radiotherapy was safely feasible in elderly patients with NSCLC, although elderly patients had a higher prevalence of higher degree hematological toxicity than younger patients.

A recent study [26] shows that patients without or with mild co-morbidities have a significantly better survival. The increasing severity of co-morbidities may sufficiently shorten the remaining life expectancy, cancel the gains obtained by radiotherapy and increase the acute lung toxicity.

Thus, based on current evidence, we recommend that elderly patients with advanced NSCLC and a good performance status be offered combined treatment. However, in the oldest/old and in frail patients, single modality treatment may be most appropriate.

\section{Small Cell Lung Cancer}

A multimodality approach consisting of radiotherapy and platinum-etoposide chemotherapy is recommended treatment for patients with limited stage SCLC. Adding chemotherapy to thoracic radiotherapy leads to an approximately $30 \%$ increase in disease control and up to $14 \%$ reduction in mortality. Combined treatment produces a significant improvement in survival of $5.4 \%$ at 3 years compared with chemotherapy alone [27,28]. From subset analyses of these two meta-analyses, it appears that the benefit is confined to younger patients (aged less than 55) with a trend toward on adverse outcome in patients aged more than 70 years. All these facts are justified by authors with an increased toxicity, however no data are available. In 1999, a retrospective review of two randomized trials of the National Cancer Institute of Canada [29] clearly demonstrated that here was no statistical difference noted with regard to the rates of RT-related toxicities, response, local control, or survival between the young and older age groups. Similarly, Yuen et al., analyzing retrospectively elderly patients in Intergroup Trial 0096 [30], showed that elderly patients had similar response and survival rates compared with those younger than 70 years. However, toxicity, particularly hematologic, was greater among the elderly. The retrospective analysis of North Central Cancer Treatment Group [31] revealed that elderly patients may experience greater toxicity due to preexisting illnesses, decreased clearance of chemotherapy, and limited bone marrow reserve. In spite of increased toxicities, elderly patients had disease control and survival rates similar to those of younger patients. In addition to these subset analyses, several reports have been published with conflicting results as some studies reported similar survival between young and elderly patients [32,33] and other studies reported lower survival for the elderly [34,35].

A less aggressive treatment approach has been investigated in two prospective phase II studies of radiochemotherapy treatment specifically designed for elderly patients with small cell lung cancer. Jeremic et al. evaluated a regimen of carboplatin and etoposide combined with accelerated hyperfractionated radiation, obtaining a 
tolerable and active regimen [36]. Murray et al. evaluated an abbreviated regimen plan consisting of two cycles of chemotherapy plus thoracic irradiation obtaining useful palliation and potential for long-term survival [37].

Concurrent radiochemotherapy can be administered to fit elderly patients with limited stage SCLC. For patients with multiple comorbidities, the sequential approach or an abbreviated approach is better alternative.

\section{Conclusions}

In geriatric oncology, the key question is to achieve the best outcomes and avoid unnecessary or ineffective treatments. Radiochemotherapy maintains its activity and feasibility in lung cancer elderly patients. It is difficult to determine a standard therapy for elderly patients based only on chronological landmarks, as the effects of aging depend on the individual. It is very important to assess comorbidity with its severity in order to aid in the development of plans for treatment.

Lung cancer elderly patients, correctly stratified, should be allowed and encouraged to participate in clinical studies.

\section{REFERENCES}

[1] A. Jemal, F. Bray, M. M. Center, J. Ferlay, E. Ward and D. Forman, "Global Cancer Statistics," A Cancer Journal for Clinicians, Vol. 61, No. 2, 2011, pp. 69-90. doi:10.3322/caac. 20107

[2] S. M. Lichtman, "Management of Advanced Colorectal Cancer in Older Patients," Oncology, Vol. 19, No. 5, 2005, pp. 597-602.

[3] M. S. Aapro, "The Frail Are Not Always Elderly," Journal of Clinical Oncology, Vol. 23, No. 10, 2005, pp. 2121-2122. doi: $10.1200 /$ JCO.2005.10.976

[4] S. Baka, L. Ashcroft, H. Anderson, M. Lind, P. Burt, R. Stout, I. Dowd, D. Smith, P. Lorigan and N. Thatcher, "Randomized Phase II Study of Two Gemcitabine Schedules for Patients with Impaired Performance Status (Karnofsky Performance Status $\leq 70$ ) and Advanced Non-Small-Cell Lung Cancer," Journal of Clinical Oncology, Vol. 23, No. 10, 2005, pp. 2136-2144. doi:10.1200/JCO.2005.01.003

[5] L. Balducci, "Geriatric Oncology," Critical Reviews in Oncology/Hematology, Vol. 46, No. 3, 2003, pp. 211-220. doi:10.1016/S1040-8428(03)00020-9

[6] S. K. Pal and A. Hurria, "Impact of Age, Sex, and Comorbidity on Cancer Therapy and Disease Progression," Journal of Clinical Oncology, Vol. 28, No. 26, 2010, pp. 4086-4093. doi:10.1200/JCO.2009.27.0579

[7] I. F. Tannock, "Treatment of Cancer with Radiation and Drugs," Journal of Clinical Oncology, Vol. 14, No. 12, 1996, pp. 3156-3174.

[8] E. E. Vokes and R. R. Weichselbaum, "Concomitant Chemoradiotherapy: Rationale and Clinical Experience in Patients with Solid Tumors," Journal of Clinical Oncol- ogy, Vol. 8, No. 5, 1990, pp. 911-934.

[9] A. Aupérin, C. Le Péchoux, E. Rolland, W. J. Curran, K. Furuse, P. Fournel, J. Belderbos, G. Clamon, H. C. Ulutin, R. Paulus, T. Yamanaka, M. C. Bozonnat, A. Uitterhoeve, X. Wang, L. Stewart, R. Arriagada, S. Burdett and J. P. Pignon, "Meta-Analysis of Concomitant versus Sequential Radiochemotherapy in Locally Advanced Non-SmallCell Lung Cancer," Journal of Clinical Oncology, Vol. 28, No. 13, 2010 pp. 2181-2190.

doi:10.1200/JCO.2009.26.2543

[10] M. Pijls-Johannesma, D. De Ruysscher, J. Vansteenkiste, A. Kester, I. Rutten and P. Lambin, "Timing of Chest Radiotherapy in Patients with Limited Stage Small Cell Lung Cancer: A Systematic Review and Meta-Analysis of Randomised Controlled Trials," Cancer Treatment Reviews, Vol. 33, No. 5, 2007, pp. 461-473.

doi:10.1016/j.ctrv.2007.03.002

[11] T. Y. Seiwert, J. K. Salama and E. E. Vokes, "The Concurrent Chemoradiation Paradigm-General Principles," Nature Clinical Practice Oncology, Vol. 4, No. 2, 2007, pp. 86-100. doi:10.1038/ncponc0714

[12] M. A. Gosney, "Clinical Assessment of Elderly People with Cancer," The Lancet Oncology, Vol. 6, No. 10, 2005, pp. 790-797. doi:10.1016/S1470-2045(05)70389-2

[13] S. Greenfield, D. M. Blanco and R. M. Elashoff, "Development and Test of a New Index of Comorbidity Index," Clinical Research, Vol. 35, No. 346, 1987.

[14] J. F. Piccirillo, R. M. Tierney, I. Costas, L. Grove and E. L. Spitznagel Jr., "Prognostic Importance of Comorbidity in a Hospital-Based Cancer Registry," The Journal of the American Medical Association, Vol. 291, No. 20, 2004, pp. 2441-2447. doi:10.1001/jama.291.20.2441

[15] M. D. Miller, C. F. Paradis, P. R. Houck, S. Mazumdar, J. A. Stack, A. H. Rifai, B. Mulsant and C. F. Reynolds III, "Rating Chronic Medical Illness Burden in Geropsychiatric Practice and Research: Application of the Cumulative Illness Rating Scale," Psychiatry Research, Vol. 41, No. 3, 1992, pp. 237-248. doi:10.1016/0165-1781(92)90005-N

[16] B. Singh, M. Bhaya, J. Stern, J. T. Roland, M. Zimbler, R. M. Rosenfeld, G. Har-El, F. E. Lucente, "Validation of the Charlson Comorbidity Index in Patients with Head and Neck Cancer: A Multi-Institutional Study," The Laryngoscope, Vol. 107, No. 11, 1997, pp. 1469-1475. doi:10.1097/00005537-199711000-00009

[17] J. Gomez-Millan, "Radiation Therapy in the Elderly: More Side Effects and Complications?" Critical Reviews in Oncology/Hematology, Vol. 71, No. 1, 2009, pp. 70-78. doi:10.1016/j.critrevonc.2008.11.004

[18] A. Jemal, R. Siegel, E. Ward, T. Murray, J. Xu, C. Smigal and M. J. Thun, "Cancer Statistics," A Cancer Journal for Clinicians, Vol. 53, No. 1, 2003, pp. 5-26. doi:10.3322/canjclin.53.1.5

[19] S. D. Ramsey, N. Howlader, R. D. Etzioni and B. Donato, "Chemotherapy Use, Outcomes, and Costs for Older Persons with Advanced Non-Small-Cell Lung Cancer: Evidence from Surveillance, Epidemiology and End ResultsMedicare," Journal of Clinical Oncology, Vol. 22, No. 24, 2004, pp. 4971-4978. 
doi:10.1200/JCO.2004.05.031

[20] M. Werner-Wasik, C. Scott, J. D. Cox, W. T. Sause, R. W. Byhardt, S. Asbell, A. Russell, R. Komaki, J. S. Lee, "Recursive Partitioning Analysis of 1999 Radiation Therapy Oncology Group (RTOG) Patients with Locally-Advanced Non-Small-Cell Lung Cancer (LA-NSCLC): Identification of Five Groups with Different Survival," International Journal of Radiation Oncology, Biology, Physics, Vol. 48, No. 5, 2000, pp. 1475-1482. doi:10.1016/S0360-3016(00)00801-4

[21] S. E. Schild, S. J. Mandrekar, A. Jatoi, W. L. McGinnis, P. J. Stella, R. L. Deming, J. R. Jett, Y. I. Garces, K. L. Allen and A. A. Adjei, "The Value of Combined-Modality Therapy in Elderly Patients with Stage III Nonsmall Cell Lung Cancer," Cancer, Vol. 110, No. 2, 2007, pp. 363368. doi: $10.1002 /$ cncr. 22780

[22] W. J. Curran Jr., R. Paulus, C. J. Langer, R. Komaki, J. S. Lee, S. Hauser, B. Movsas, T. Wasserman, S. A. Rosenthal, E. Gore, M. Machtay, W. Sause and J. D. Cox, "Sequential versus Concurrent Chemoradiation for Stage III Non-Small Cell Lung Cancer: Randomized Phase III Trial," Journal of the National Cancer Institute, Vol. 103, No. 19, 2011, pp. 1452-1460. doi:10.1093/jnci/djr325

[23] C. J. Langer, C. Hsu and W. J. Curran, "Elderly Patients with Locally Advanced Non-Small Cell Lung Cancer Benefit from Combined Modality Therapy: Secondary Analysis of Radiation Therapy Oncology Group (RTOG) 94-10," Program Proceedings-American Society of Clinical Oncology Program Oncol, Vol. 21, No. 29a, 2002.

[24] C. M. S. R. Lima, J. E., Herndon II, M. Kosty, G. Clamon and M. R. Green, "Therapy Choices among Older Patients with Lung Carcinoma: An Evaluation of Two Trials of the Cancer and Leukemia Group B," Cancer, Vol. 94, No. 1, 2002, pp. 181-187. doi:10.1002/cncr.10174

[25] S. Semrau, G. Klautke, J. C. Virchow, G. Kundt and R. Fietkau, "Impact of Comorbidity and Age on the Outcome of Patients with Inoperable NSCLC Treated with Concurrent Chemoradiotherapy," Respiratory Medicine, Vol. 102, No. 2, 2008, pp. 210-218.

doi:10.1016/j.rmed.2007.09.009

[26] F. Fiorica, F. Cartei, S. Ursino, A. Stefanelli, Y. Zagatti, S. Berretta, S. Figura, D. Maugeri, E. Zanet, D. Spartà, C. La Morella, U. Tirelli and M. Berretta, "Safety and Feasibility of Radiotherapy Treatment in Elderly Non-SmallCell Lung Cancer (NSCLC) Patients," Archives of Gerontology and Geriatrics, Vol. 50, No. 2, 2010, pp. 185191. doi:10.1016/j.archger.2009.03.008

[27] J. P. Pignon, R. Arriagada, D. C. Ihde, D. H. Johnson, M. C. Perry, R. L. Souhami, O. Brodin, R. A. Joss, M. S. Kies, B. Lebeau, et al., "A Meta-Analysis of Thoracic Radiotherapy for Small-Cell Lung Cancer," The New England Journal of Medicine, Vol. 327, No. 23, 1992, pp. 1618-1624. doi:10.1056/NEJM199212033272302

[28] P. Warde and D. Payne, "Does Thoracic Irradiation Improve Survival and Local Control in Limited-Stage Small-Cell Carcinoma of the Lung? A Meta-Analysis," Journal of Clinical Oncology, Vol. 10, No. 6, 1992, pp. 890-895.

[29] H. Quon, F. A. Shepherd, D. G. Payne, P. Coy, N.
Murray, R. Feld, J. Pater, A. Sadura and B. Zee, "The Influence of Age on the Delivery, Tolerance, and Efficacy of Thoracic Irradiation in the Combined Modality Treatment of Limited Stage Small Cell Lung Cancer," International Journal of Radiation Oncology, Biology, Physics, Vol. 43, No. 1, 1999, pp. 39-45. doi:10.1016/S0360-3016(98)00373-3

[30] A. R. Yuen, G. Zou, A. T. Turrisi, W. Sause, R. Komaki, H. Wagner, S. C. Aisner, R. B. Livingston, R. Blum and D. H. Johnson, "Similar Outcome of Elderly Patients in Intergroup Trial 0096: Cisplatin, Etoposide, and Thoracic Radiotherapy Administered Once or Twice Daily in Limited Stage Smallcell Lung Carcinoma," Cancer, Vol. 89, No. 9, 2000, pp. 1953-1960.

doi:10.1002/1097-0142(20001101)89:9<1953::AID-CNC R11>3.3.CO;2-Y

[31] S. E. Schild, P. J. Stella, B. J. Brooks, S. Mandrekar, J. A. Bonner, W. L. McGinnis, J. A. Mailliard, J. E. Krook, R. L. Deming, A. A. Adjei, A. Jatoi and J. R. Jett, "Results of Combined-Modality Therapy for Limited-Stage Small Cell Lung Carcinoma in the Elderly," Cancer, Vol. 103, 11, 2005, pp. 2349-2354. doi:10.1002/cncr.21034

[32] C. Jara, J. L. Gómez-Aldaraví, R. Tirado, V. A. Meseguer, C. Alonso and A. Fernández, "Small-Cell Lung Cancer in the Elderly-Is Age of Patient a Relevant Factor?" Acta Oncologica, Vol. 38, No. 6, 1999, pp. 781-786. doi:10.1080/028418699432941

[33] E. Dajczman, L. Y. Fu, D. Small, N. Wolkove and H. Kreisman, "Treatment of Small Cell Lung Carcinoma in the Elderly," Cancer, Vol. 77, No. 10, 1996, pp. 20322038.

doi:10.1002/(SICI)1097-0142(19960515)77:10<2032::AI D-CNCR10>3.0.CO;2-W

[34] J. J. Ludbrook, P. T. Truong, M. V. MacNeil, M. Lesperance, A. Webber, H. Joe, H. Martins and J. Lim, "Do Age and Comorbidity Impact Treatment Allocation and Outcomes in Limited Stage Small-Cell Lung Cancer? A Community-Based Population Analysis," International Journal of Radiation Oncology, Biology, Physics, Vol. 55, No. 5, 2003, pp. 1321-1330.

doi:10.1016/S0360-3016(02)04576-5

[35] E. Nõu, "Full Chemotherapy in Elderly Patients with Small Cell Bronchial Carcinoma," Lung Cancer, Vol. 16, No. 2, 1997, pp. 277-277. doi: $10.3109 / 02841869609109912$

[36] B. Jeremic, Y. Shibamoto, L. Acimovic and S. Milisavljevic, "Carboplatin, Etoposide, and Accelerated Hyperfractionated Radiotherapy for Elderly Patients with Limited Small Cell Lung Carcinoma: A Phase II Study," Cancer, Vol. 82, No. 5, 1998, pp. 836-841. doi:10.1002/(SICI)1097-0142(19980301)82:5<836::AIDCNCR6>3.0.CO;2-H

[37] N. Murray, C. Grafton, A. Shah, K. Gelmon, E. Kostashuk, E. Brown, C. Coppin, A. Coldman and R. Page "Abbreviated Treatment for Elderly, Infirm, or Noncompliant Patients with Limited-Stage Small-Cell Lung Cancer," Journal of Clinical Oncology, Vol. 16, No. 10, 1998, pp. 3323-3328. 